\title{
Impact of immunohistochemistry-based molecular subtype on chemosensitivity and survival in Hispanic breast cancer patients following neoadjuvant chemotherapy
}

\author{
Rodolfo Gómez ${ }^{1,2,3}$, Carlos Andrés Ossa ${ }^{1,3}$, María Elvira Montoya ${ }^{1,3}$, Carolina Echeverri ${ }^{1}$, Gonzalo Ángel ${ }^{1,3}$, Johana Ascuntar ${ }^{1}$,

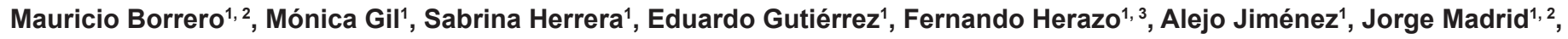 \\ Pedro Alejandro Reyes ${ }^{1}$, Lina Zuluaga1 and Héctor García1, 3,4
}

${ }^{1}$ Instituto de Cancerología-Clínica Las Américas, Medellín 05001000, Colombia

${ }^{2}$ School of Medicine, Universidad de Antioquia, Medellín, Colombia

${ }^{3}$ Cancer Research Group, Instituto de Cancerología-Clínica Las Américas, Medellín 05001000, Colombia

${ }^{4}$ School of Medicine, Clinical Epidemiology Academic Group (GRAEPIC), Universidad de Antioquia, Medellín, Colombia

Correspondence to: Rodolfo Gómez. Email: Irgomez@idclasamericas.co

\section{Abstract}

Background: Neoadjuvant chemotherapy (NAC) is the standard treatment for patients with locally advanced breast cancer, showing improvement in disease-free survival (DFS) and overall survival (OS) rates in patients achieving pathological complete response (pCR). The relationship between immunohistochemistry-based molecular subtyping (IMS), chemo sensitivity and survival is currently a matter of interest. We explore this relationship in a Hispanic cohort of breast cancer patients treated with NAC.

Methods: A retrospective survival analysis was performed on Colombian females with breast cancer treated at Instituto de CancerologíaClinica Las Américas between January 2009 and December 2011. Patients were classified according to immunohistochemistry-based subtyping into the following five groups: Luminal A, Luminal B, Luminal B/HER 2+, HER2-enriched, and triple-negative breast cancer. Demographic characteristics, recurrence pattern, and survival rate were reviewed by bivariate and multivariate analysis.

ecancer 2015, 9:562 DOI: 10.3332/ecancer.2015.562

Copyright: (c) the authors; licensee ecancermedicalscience. This is an Open Access article distributed under the terms of the Creative Commons Attribution License (http://creativecommons.org/licenses/by/3.0), which permits unrestricted use, distribution, and reproduction in any medium, provided the original work is properly cited. 
Results: A total of 328 patients fulfilled the study's inclusion parameters and the distribution of subtypes were as follows: Luminal A: 73 (22.3\%), Luminal B/HER2-: 110 (33.5\%), Luminal B/HER2+: 75 (22.9\%), HER2-enriched: 30 (9.1\%), and triple-negative: 40 (12.2\%). The median follow-up was 41 months (interquartile range: 31-52). Pathological response to NAC was as follows: complete pathological response (pCR) in $28(8.5 \%)$ patients, partial 247 (75.3\%); stable disease $47(14.3 \%)$, and progression $6(1.8 \%)$ patients. The presence of pCR had a significant DFS and OS in the entire group $(p=0.01)$ but subtypes had different DFS in Luminal B $(p=0.01)$ and triple negative $(p=0.02)$ and also OS in Luminal $\mathrm{B}(p=0.01)$ and triple negative $(p=0.01)$.

Conclusions: pCR is associated with an improved overall survival and disease-free survival rates in this group of Hispanics patients. Advanced stages, Luminal B subtypes, triple-negative tumours and non-pCR showed lower DFS.

Keywords: breast cancer, Colombia, Hispanics, intrinsic subtypes, molecular subtypes, neoadjuvant therapy, pathological complete response

\section{Introduction}

Neodjuvant chemotherapy (NAC) has proven either to decrease tumour size in cancer patients not suitable for primary surgery or to increase the possibility of conservative surgery when it had previously been inadvisable. Currently, it must be considered an evaluative tool in designing a therapeutic strategy or biological factors that may help to determine the prognosis and treatment alternatives in a given patients.

NAC has shown as significantly improved disease-free survival (DFS) and overall survival (OS) rates as adjuvant therapy in patients with breast cancer [1]; moreover, it has become the standard procedure when handling non-surgical tumours and inflammatory carcinomas [2]. It increases the proportion rate of conservative surgeries in patients with locally advanced breast cancer tumours [3] and decreases resection extension even in patients scheduled for conservative surgery [4].

In the last few years, breast cancer intrinsic molecular subtypes have been evaluated by gene expression array data, a technology not widely available worldwide. Immunohistochemistry-based molecular subtype with ER, PR, Ki67, and HER2 Neu has shown good correlation with gene expression assays to identify intrinsic subtypes [5].

Previous reports state that not all patients have an equal response to NAC and that this response may vary depending on biological characteristics of the tumour and their immunohistochemistry-based molecular subtype, In basal-like tumours achieving a complete pathological response $(\mathrm{pCR})$ rate in $45 \%(95 \% \mathrm{Cl}$ : 24-68), HER2+ in $45 \%(95 \% \mathrm{Cl}: 23-68)$, and Luminal A in 6\% (95\%Cl:1-21) [6].

Some publications suggest that $\mathrm{pCR}$ could be a surrogate marker for OS, particularly in the triple-negative and HER2 subgroups, with HER2+/ hormone receptor (HR)-negative presenting a higher OS rate than HER2+/HR+ patients [7]. Although pCR has proven to be consistently associated with an excellent survival rate, it is not the only prognostic factor, as in cases of less aggressive tumours like Luminal A.

Achieving $\mathrm{pCR}$ at the time of surgery has been associated with a favourable prognosis [8,9]. Not achieving pCR has shown worse results in triple-negative and HER2+ tumours, although this prognostic correlation has not been observed in HR+ tumours [9, 10].

This study aims to determine the pathological response and its correlation with breast cancer immunohistochemistry-based molecular subtype as well as its correlation with DFS and OS rates in patients who have undergone NAC at Instituto de Cancerología- Clínica Las Américas (IDC), a comprehensive cancer centre in Colombia.

\section{Patients and Methods}

A retrospective survival study was performed in women older than 18 years of age treated with NAC at the IDC between January 2009 and December 2011.

The study included patients with histological diagnosis of breast cancer, Stages II and III, who received NAC, breast surgery and had a histopathological assay in our centre (Figure 1). Neither patients with Stage IV at the time of diagnosis nor patients receiving fewer than three NAC cycles were included. The same was for patients without complete IHC information available. 


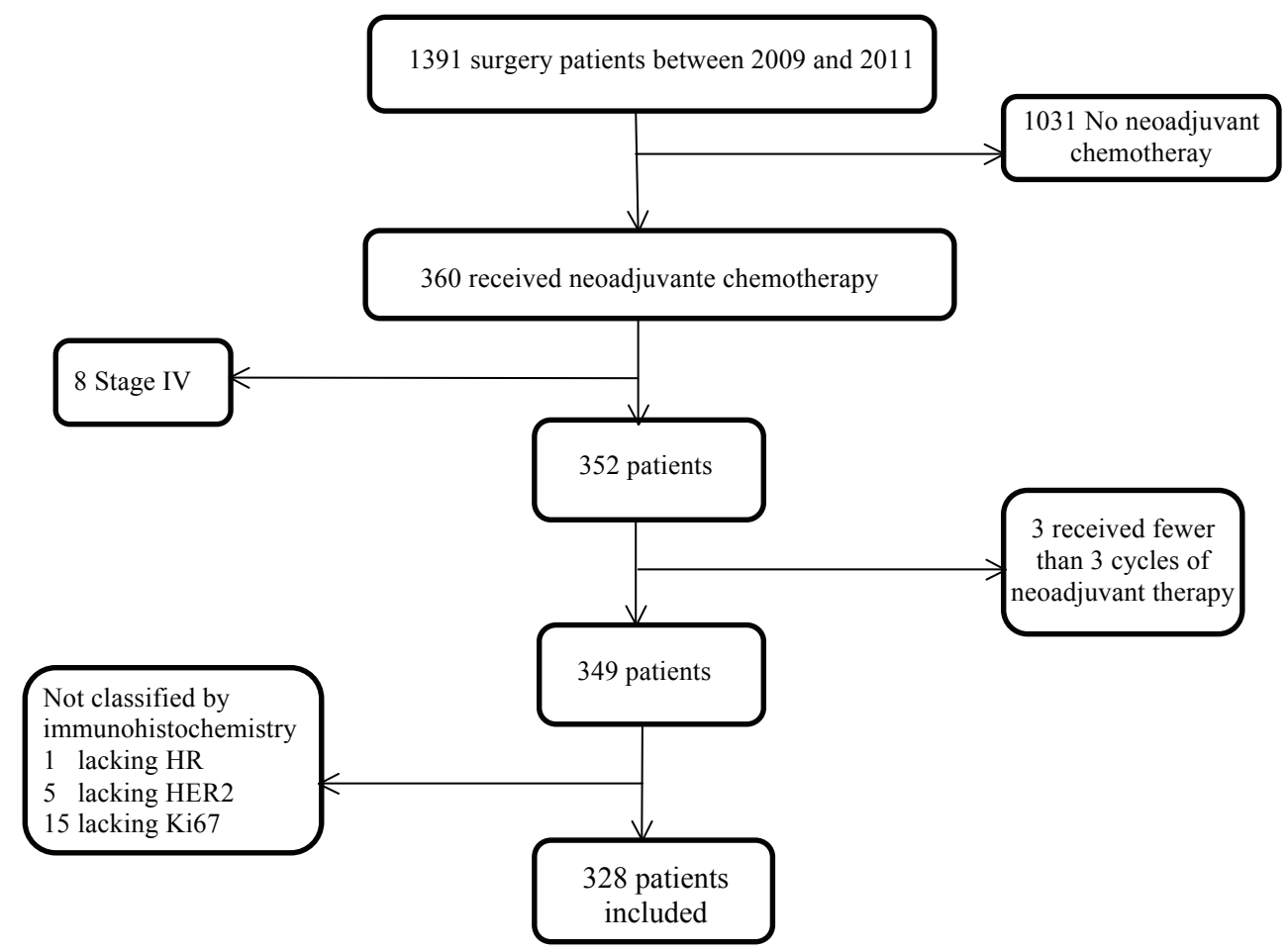

Figure 1. Study profile.

All demographic, clinical, and follow-up variables were obtained from the IDC patient's registry, medical records, and surgical pathology reports. Pathology reports follow the College of American Pathologists (CAP) checklists. The ER, PR, and HER2 Neu were evaluated following the published CAP guideline recommendations [11, 12]. Antibody clones were used: ER clone SP1 (Thermo scientific, USA), PR clone 16 (Leica Biosystems, Germany), Monoclonal Mouse Anti-Human Ki-67 Antigen (Dako, Denmark), and HER-2/neu (4B5) Rabbit Monoclonal Primary Antibody (Ventana, USA) was used in the majority of cases. The Ki-67 was performed in some cases when it was not carried out in initial pathology study, using the MIB1 antibody (Dako, Glostrup, Denmark). Ki-67 cut-off to separate low and high risk was $14 \%$ as proposed by Consensus [13].

Patient's vital status was traced through phone calls. IDC's IRB approved the research project.

Hormone receptor status (ER and PR) is considered positive if IHC staining is $\geq 1 \%$. HER2 is positive in tumours showing IHC +++ or IHC ++ by positive FISH ( $\geq 2.4)$.

Immunohistochemistry-based molecular subtypes definition:

'Luminal A': ER+ and/or PR+, HER2-, Ki-67 < 14\%

'Luminal B': ER+ and/or PR+, HER2-, Ki-67 $\geq 14 \%$

'Luminal B/HER 2+': ER+ and/or PR+, HER2+

'HER2-enriched': ER- and PR-, HER2+

'Triple negative': ER-, PR-, HER2-

The chemotherapy schema utilised were znthracyclines and taxanes, anthracyclines alone, and taxanes only. Patients who had contraindicated the use of anthracyclines was included in the taxane scheme (docetaxel-cyclophosphamide) or treated with cyclophosphamide, methotrexate, and fluorouracil (CMF).

As described in a recent paper, a pCR was defined as ypT0 ypN0 (the absence of invasive cancer and in situ cancer in the breast and axillary nodes) [14]. 


\section{Statistical Analysis}

Bivariate analysis by intrinsic subtypes was performed. The chi-square or Fisher's exact test were used for the categorical variables, and the $t$-test or one-way analysis of variance (ANOVA) was used for numeric variables. Survival rate was calculated up until the date of relapse, death, or last control check. Kaplan-Meier curves were assessed according to pCR, subtypes and clinical variables that were compared with a Breslow test. In the multivariate analysis, all variables with clinical or statistical significance $(p<0.25)$ in bivariate analysis were included. All variables were categorised for multivariable analysis. Adjusting for potential confounders was performed with Cox regression analysis. The statistical significance for the variables included in the multivariate model was set at a level of statistical significance of $p<0.05$. A two-tailed $p$ value was established at $>0.05$. SPSS software (version 20.0; SPSS, Chicago, IL) was used in the statistical analysis.

\section{Results}

Table 1 shows the population's clinical characteristics. A total of 328 patients within $24-81$ years of age fulfilled the inclusion criteria. The mean age was of 52.9 years (standard deviation: 11.3$)$, and $83(25.3 \%)$ patients were younger than 45 years of age.

Table 1. Clinical characteristics of population.

\begin{tabular}{|c|c|}
\hline Charact & \\
\hline Mean age (sd) & $52.9(11.3)$ \\
\hline Age groups & -0.6 \\
\hline$<45$ years & $83(25.3 \%)$ \\
\hline $45-54$ years & $103(31.4 \%)$ \\
\hline$\geq 55$ years & $142(43.3 \%)$ \\
\hline \multicolumn{2}{|l|}{ Clinical stage } \\
\hline IIA & $25(7.6 \%)$ \\
\hline IIB & $40(12.2 \%)$ \\
\hline IIIA & $68(20.8 \%)$ \\
\hline IIIB & $183(55.7 \%)$ \\
\hline IIIC & $12(3.7 \%)$ \\
\hline \multicolumn{2}{|l|}{ Histological variety } \\
\hline Ductal & $300(91.5 \%)$ \\
\hline Lobular & $17(5.2 \%)$ \\
\hline Other & $11(3.3 \%)$ \\
\hline \multicolumn{2}{|l|}{ Histological grade } \\
\hline 1 & $46(14.0 \%)$ \\
\hline 2 & $122(37.2 \%)$ \\
\hline 3 & $160(48.8 \%)$ \\
\hline \multicolumn{2}{|l|}{ Tumour size (mm) } \\
\hline$<30$ & $19(6.2 \%)$ \\
\hline$\geq 30$ & $288(93.8 \%)$ \\
\hline \multicolumn{2}{|l|}{ Type of surgery } \\
\hline Quadrantectomy & $102(31.1 \%)$ \\
\hline Mastectomy & $226(68.9 \%)$ \\
\hline Reconstruction & $37(16.4 \%)$ \\
\hline
\end{tabular}


Table 1. (Continued).

\begin{tabular}{|c|c|}
\hline Sentinel lymph node & $28(8.5 \%)$ \\
\hline Axillary clearance & $307(93.6 \%)$ \\
\hline \multicolumn{2}{|l|}{ Positive lymph nodes at clearance } \\
\hline Negative & $120(39.1 \%)$ \\
\hline 1 to 3 & $88(28.7 \%)$ \\
\hline 4 to 9 & $60(19.5 \%)$ \\
\hline$\geq 10$ & $39(12.7 \%)$ \\
\hline \multicolumn{2}{|l|}{ Hormone receptor status } \\
\hline Estrogen receptor positive & $252(76.8 \%)$ \\
\hline Progesterone receptor positive & $197(60.1 \%)$ \\
\hline HER2/neupositive & $105(32.0 \%)$ \\
\hline \multicolumn{2}{|l|}{ KI-67 score } \\
\hline$\leq 14$ & $140(42.7 \%)$ \\
\hline$>14$ & $188(57.3 \%)$ \\
\hline \multicolumn{2}{|l|}{ Neoadjuvant chemotherapy regimen } \\
\hline Anthracycline-based only & $46(14.0 \%)$ \\
\hline Anthracycline and taxane based & $272(82.9 \%)$ \\
\hline Taxane-based only & $6(1.8 \%)$ \\
\hline $\mathrm{CFM}^{*}$ & $4(1.2 \%)$ \\
\hline \multicolumn{2}{|l|}{ HER2/neu-Trastuzumab } \\
\hline HER2/neu-Yes Trastuzumab & $89(84.8 \%)$ \\
\hline HER2/neu-No Trastuzumab & $16(15.2 \%)$ \\
\hline \multicolumn{2}{|l|}{ Metastasis and/or relapse } \\
\hline Local & $9(11.8 \%)$ \\
\hline Metastasis & $67(88.2 \%)$ \\
\hline
\end{tabular}

"CFM: cyclophosphamide, methotrexate, and fluorouracil

Sixty-five (19.8\%) patients were Stage II and 263 (80.2\%) Stage III; tumour size was $\geq 30 \mathrm{~mm}$ in $93.8 \%$ of patients. The chemotherapy schema used was anthracyclines and taxanes in $272(82.9 \%)$, anthracycline alone in $46(14.1 \%)$, taxanes only in $6(1.8 \%)$ and CMF in the remaining $4(1.2 \%)$ patients. Out of $105(32 \%)$ patients with HER2-positive cases $87(82.9 \%)$ received trastuzumab in the neoadjuvant setting.

After neoadjuvant chemotherapy, 226 (68.9\%) patients had mastectomy, 37 (11.3\%) of them with early reconstruction, and breast-conserving surgery in 102 (31.1\%). According to our institutional protocol at that time, axillar dissection was performed directly in 307 (93.6\%) cases, and sentinel lymph node post-NAC was performed in only 28 (8.5\%) patients.

Involved lymph nodes were found in 187 (57.7\%) cases: 88 had 1-3, 60 from 4-9, and in 39, more than nine were involved.

Immunohistochemistry-based molecular subtype distribution was as follows: 'Luminal A': 73 (22.3\%); 'Luminal B': 110 (33.5\%); 'Luminal B/ HER2+': 75 (22.9\%); 'HER2-enriched': 30 (9.1\%); and 'triple negative': 40 (12.2\%). Table 2 shows the clinical characteristics according to intrinsic subtype. 
Table 2. Response to neoadjuvant chemotherapy by molecular subtypes.

\begin{tabular}{|c|c|c|c|c|c|c|c|}
\hline & $\begin{array}{c}\text { Luminal A } \\
73(22.3) \\
\#(\%)\end{array}$ & $\begin{array}{l}\text { Luminal B } \\
\begin{array}{c}110(33.5) \\
\#(\%)\end{array}\end{array}$ & $\begin{array}{c}\text { Luminal B } \\
\text { HER2 + } \\
75(22.9) \\
\#(\%)\end{array}$ & $\begin{array}{c}\text { HER2- } \\
\text { enriched } \\
30(9.1) \\
\#(\%)\end{array}$ & $\begin{array}{c}\text { Triple } \\
\text { negative } \\
40(12.2) \\
\#(\%)\end{array}$ & $\begin{array}{c}\text { Total } \\
328 \\
\#(\%)\end{array}$ & $p$ value \\
\hline \multicolumn{7}{|l|}{ Response to NAC } & \multirow[b]{5}{*}{$<0.01$} \\
\hline NAC progression & $0(0.0)$ & $3(2.7)$ & $0(0.0)$ & $2(6.7)$ & $1(2.5)$ & $6(1.8)$ & \\
\hline Stable disease & $6(8.2)$ & $24(21.8)$ & $10(13.3)$ & $3(10.0)$ & $4(10.0)$ & $47(14.3)$ & \\
\hline Partial response & $67(91.8)$ & $80(72.7)$ & $55(73.3)$ & $21(70.0)$ & $24(60.0)$ & $247(75.3)$ & \\
\hline Complete response (pCR) & $0(0.0)$ & $3(2.7)$ & $10(13.3)$ & $4(13.3)$ & $11(27.5)$ & $28(8.5)$ & \\
\hline
\end{tabular}

$p$-value for the comparison of $\mathrm{pCR}$ versus non-pCR between subtypes

Median time elapsed between histopathological diagnosis and NAC was 56 days (IQR: 34-103), median time of duration of NAC was 175 days (IQR: 144-193). 271 (82.6\%) patients received the whole-planned chemotherapy schema. Of the remaining 57 cases, 15 had drug intolerance, 10 disease progression, 13 poor drug response, six due insurance coverage issues, six because of patients desire, and seven for different comorbidities.

Overall frequency of pCR was $8.5 \%(n=28)$, partial responses in $75.3 \%(n=247)$, the disease remained stable in $14.3 \%(n=47)$, and there was progression in $1.8 \%(n=6)$ patients. The rates of pCR differed $(p<0.01)$ among subtypes: $27.5 \%$ of 'Triple negative', $13.3 \%$ of 'HER2-enriched', $13.5 \%$ of 'Luminal B/HER2+', $2.7 \%$ of 'Luminal B', and none in 'Luminal A' (Table 3).

Table 3. Clinical characteristics of intrinsic subtypes.

\begin{tabular}{|c|c|c|c|c|c|c|}
\hline Characteristics & $\begin{array}{l}\text { Luminal A } \\
\begin{array}{c}73(22.3 \%) \\
\#(\%)\end{array}\end{array}$ & $\begin{array}{l}\text { Luminal B } \\
\begin{array}{c}110(33.5 \%) \\
\#(\%)\end{array}\end{array}$ & $\begin{array}{c}\text { Luminal B/ } \\
\text { HER2+ } \\
75(22.9 \%) \\
\#(\%)\end{array}$ & $\begin{array}{c}\text { HER2- } \\
\text { enriched } \\
30(9.1 \%) \\
\#(\%)\end{array}$ & $\begin{array}{c}\text { Triple } \\
\text { negative } \\
40(12.2 \%) \\
\#(\%)\end{array}$ & $p$-value \\
\hline Mean age (de) & $51.9(9.6)$ & $54.1(11.4)$ & $51.7(11.8)$ & $51.4(11.2)$ & $54.6(13.0)$ & 0.40 \\
\hline \multicolumn{7}{|l|}{ Age groups } \\
\hline$<45$ years & $16(21.9)$ & $26(23.6)$ & $22(29.3)$ & $10(33.3)$ & $9(22.5)$ & \multirow{3}{*}{0.14} \\
\hline 45 - 54 years & $31(42.5)$ & $28(25.5)$ & $26(34.7)$ & $9(30.0)$ & $9(22.5)$ & \\
\hline$\geq 55$ years & $26(35.6)$ & $56(50.9)$ & $27(36.0)$ & $11(36.7)$ & $22(55.0)$ & \\
\hline \multicolumn{7}{|l|}{ Clinical stage $^{*}$} \\
\hline IIA & $8(10.9)$ & $6(5.5)$ & $5(6.7)$ & $0(0.0)$ & $6(15.0)$ & \multirow{5}{*}{0.03} \\
\hline IIB & $9(12.3)$ & $11(10.0)$ & $11(14.7)$ & $4(13.3)$ & $5(12.5)$ & \\
\hline IIIA & $10(13.7)$ & $22(20.0)$ & $16(21.3)$ & $8(26.7)$ & $12(30.0)$ & \\
\hline IIIB & $46(63.1)$ & $61(55.5)$ & $42(56.0)$ & $17(56.7)$ & $17(42.5)$ & \\
\hline IIIC & $0(0.0)$ & $10(9.1)$ & $1(1.3)$ & $1(3.3)$ & $0(0.0)$ & \\
\hline \multicolumn{7}{|l|}{ Histological variety } \\
\hline Ductal & $61(83.5)$ & $98(89.2)$ & $73(97.4)$ & $30(100)$ & $38(95.0)$ & \multirow{3}{*}{0.08} \\
\hline Lobular & $7(9.6)$ & $8(7.2)$ & $1(1.3)$ & 0 & $1(2.5)$ & \\
\hline Other & $5(6.9)$ & $4(3.6)$ & $1(1.3)$ & 0 & $1(2.5)$ & \\
\hline \multicolumn{7}{|l|}{ Histological grade* } \\
\hline 1 & $24(32.8)$ & $9(8.2)$ & $8(10.7)$ & $3(10.0)$ & $2(5.0)$ & \multirow{3}{*}{0.001} \\
\hline 2 & $38(52.0)$ & $39(35.5)$ & $26(34.7)$ & $9(30.0)$ & $10(25.0)$ & \\
\hline 3 & $11(15.2)$ & $62(56.4)$ & $41(54.7)$ & $18(60.0)$ & $28(70)$ & \\
\hline
\end{tabular}


Table 3. (Continued).

\begin{tabular}{|c|c|c|c|c|c|c|}
\hline Tumour size (mm) & & & & & & \\
\hline$<30$ & $4(5.7)$ & $5(4.8)$ & $7(10.6)$ & $0(0.0)$ & $3(7.9)$ & \multirow{2}{*}{0.32} \\
\hline$\geq 30$ & $66(94.3)$ & $99(95.2)$ & $59(89.4)$ & $29(100)$ & $35(92.1)$ & \\
\hline \multicolumn{7}{|l|}{ Type of surgery ${ }^{*}$} \\
\hline Quadrantectomy & $22(30.1)$ & $33(30.0)$ & $23(30.7)$ & $4(13.3)$ & $20(50.0)$ & \multirow{2}{*}{0.02} \\
\hline Mastectomy & $51(69.9)$ & $77(70.0)$ & $52(69.3)$ & $26(86.7)$ & $20(50.0)$ & \\
\hline Sentinel lymph node* & $3(4.1)$ & $7(6.4)$ & $10(13.3)$ & $1(3.3)$ & $7(17.5)$ & 0.04 \\
\hline Axillary clearance & $70(95.9)$ & $104(94.6)$ & $69(92.0)$ & $30(100)$ & $34(85.0)$ & 0.08 \\
\hline \multicolumn{7}{|l|}{$\begin{array}{l}\text { Positive lymph nodes at } \\
\text { clearance* }\end{array}$} \\
\hline Negative & $23(32.9)$ & $33(31.7)$ & $31(44.9)$ & $14(46.7)$ & $19(55.9)$ & \multirow{4}{*}{0.002} \\
\hline 1 to 3 & $25(35.7)$ & $26(25.0)$ & $24(34.8)$ & $9(30.0)$ & $4(11.8)$ & \\
\hline 4 to 9 & $19(27.1)$ & $23(22.1)$ & $8(11.6)$ & $2(6.7)$ & $8(23.5)$ & \\
\hline$\geq 10$ & $3(4.3)$ & $22(21.2)$ & $6(8.7)$ & $5(16.7)$ & $3(8.8)$ & \\
\hline \multicolumn{7}{|l|}{ KI-67 score ${ }^{*}$} \\
\hline$\leq 14$ & $73(100)$ & $0(0.0)$ & $38(50.7)$ & $14(46.7)$ & $15(37.5)$ & \multirow{2}{*}{0.001} \\
\hline$>14$ & $0(0.0)$ & $110(100)$ & $37(49.3)$ & $16(53.3)$ & $25(62.5)$ & \\
\hline \multicolumn{7}{|l|}{ HER2/neu-Trastuzumab } \\
\hline HER2/neu-Yes Trastuzumab & NA & NA & $64(85.3)$ & $25(83.3)$ & NA & \multirow{2}{*}{0.79} \\
\hline HER2/neu-No Trastuzumab & NA & NA & $11(14.7)$ & $5(16.7)$ & NA & \\
\hline \multicolumn{7}{|l|}{$\begin{array}{l}\text { Neoadjuvant chemotherapy } \\
\text { regimen }\end{array}$} \\
\hline Anthracycline based only & $8(11.0)$ & $18(16.4)$ & $15(20.0)$ & $1(3.3)$ & $4(10.0)$ & \multirow{4}{*}{0.20} \\
\hline $\begin{array}{l}\text { Anthracycline and taxane } \\
\text { based }\end{array}$ & $65(89.0)$ & $86(78.2)$ & $58(77.3)$ & $29(96.7)$ & $34(85.0)$ & \\
\hline Taxane-based only & $0(0.0)$ & $3(2.7)$ & $1(1.3)$ & $0(0.0)$ & $2(5.0)$ & \\
\hline $\mathrm{CFM}^{* *}$ & $0(0.0)$ & $3(2.7)$ & $1(1.3)$ & $0(0.0)$ & $0(0.0)$ & \\
\hline \multicolumn{7}{|l|}{ Metastasis and/or relapse } \\
\hline Local & $1(12.5)$ & $5(11.4)$ & $2(14.3)$ & $0(0.0)$ & $1(20.0)$ & \multirow{2}{*}{0.89} \\
\hline Metastasis & $7(87.5)$ & $39(88.6)$ & $12(85.7)$ & $5(100)$ & $4(80.0)$ & \\
\hline
\end{tabular}

In 328 patients, we evaluate the Ki-67 $\leq 14$. Among the 140 patients with Ki-67 $\leq 14,20 / 140$ patients (14.3\%) had pCR, versus 8/188 patients $(8.5 \%)$ had pCR with Ki-67 >14 $(p<0.05)$. despite finding statistical significance. In multivariate analysis, no association was found in DFS and OS for ki67.

About 225 of our patients (68.6\%) receive hormonotherapy as a adjuvant treatment, tamoxifen (202) was the upfront medication in this group of patients in the majority of the cases $89.9 \%$.

Median follow-up was 41 months (IQR: 31-52). Alive without disease evidence 213 (64.9\%), alive with active disease 26 (7.9\%), 78 (23.8\%) had died, and $11(3.3 \%)$ were missing from the follow-up.

The DFS and OS rates differed according to the intrinsic subtype $(p<0.01)$ (Figure 2). Differences in the DFS rate were found between women who achieved pCR versus non-pCR $(p=0.03)$ (Figure 3$)$, but not OS rate $(p>0.05)$. 

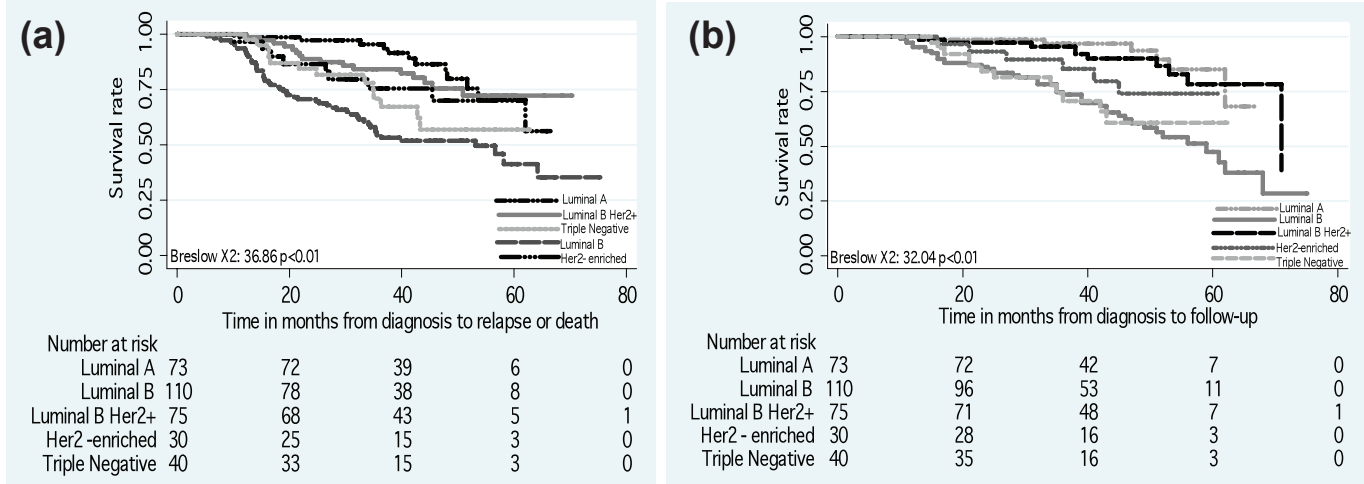

Figure 2. (a) Disease-free survival and (b) overall survival by intrinsic subtypes.

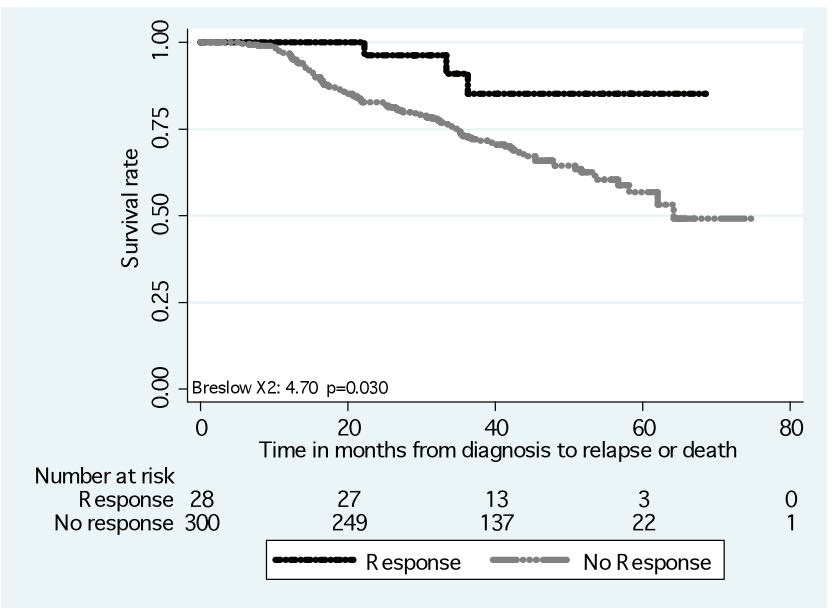

Figure 3. Disease-free survival in response to neoadjuvant chemotherapy.

The multivariable models are depicted in Table 4. After adjusting for confounders, the OS was poor in patients did not achieve pCR to NAC (HR: 5.43; 95\%Cl: 1.26-23.3); 'Luminal B subtype' (HR: 5.12; 95\%Cl: 2.18-12.05); 'triple-negative' subtype (HR: 7.41; 95\%Cl: 2.73-20.14), and clinical Stage III (HR: 3.43; 95\% Cl: 1.38-8.54). The variables associated with worse DFS were not achieve pCR to NAC (HR: 3.96; 95\%Cl 1.21-12.9); 'Luminal B' subtype (HR: 3.19; 95\%Cl: 1.66-6.14); 'triple-negative' subtype (HR: 2.62; 95\%Cl: 1.14-6.00) and histological grade 3 (HR: 1.66; 95\% Cl: 1.09-2.54).

\section{Discussion}

In the analysis of the results of our study, some important characteristics from the patients treated with NAC in our centre were considered. First, $80.2 \%$, in patients had locally advanced tumours (Stage III), implying a larger tumour load and lower survival expectancy. This could also explain why the most common surgeries for these patients were mastectomy $(68.9 \%)$. 
Table 4. Multivariable Cox regression models to overall survival (OS) and disease-free survival (DFS).

\begin{tabular}{|c|c|c|c|c|c|c|}
\hline \multirow{2}{*}{ Characteristics } & \multicolumn{3}{|c|}{ os } & \multicolumn{3}{|c|}{ DFS } \\
\hline & HR & $95 \% \mathrm{Cl}$ & $p$ value & HR & $95 \% \mathrm{Cl}$ & $p$ value \\
\hline \multicolumn{7}{|l|}{ Response to NAC } \\
\hline Complete response & 1.00 & & & 1.00 & & \\
\hline No response & 5.43 & $1.26-23.3$ & 0.02 & 3.96 & $1.21-12.9$ & 0.02 \\
\hline \multicolumn{7}{|l|}{ Intrinsic subtypes } \\
\hline Luminal A & 1.00 & & & 1.00 & & \\
\hline Luminal B & 5.12 & $2.18-12.05$ & 0.01 & 3.19 & $1.66-6.14$ & 0.01 \\
\hline Luminal B/HER2+ & 1.58 & $0.57-4.38$ & 0.37 & 1.28 & $0.59-2.76$ & 0.51 \\
\hline HER2 - enriched & 2.84 & $0.91-8.83$ & 0.07 & 1.60 & $0.63-4.03$ & 0.31 \\
\hline Triple negative & 7.41 & $2.73-20.14$ & 0.01 & 2.62 & $1.14-6.00$ & 0.02 \\
\hline \multicolumn{7}{|l|}{ Histological grade } \\
\hline 1 and 2 & & No significant & & 1.00 & & \\
\hline 3 & & & & 1.66 & $1.09-2.54$ & 0.01 \\
\hline \multicolumn{7}{|l|}{ Clinical stage } \\
\hline II & 1.00 & & & & No significant & \\
\hline III & 3.43 & $1.38-8.54$ & 0.01 & & & \\
\hline
\end{tabular}

The immunohistochemistry-based molecular subtype distribution of our patients, both in this neoadjuvant group and in our database [15] show differences from previously published data of developed countries [10,16-17] and even with other Latin American series such as Mexico that report only $57 \%$ of positive hormone receptors (HR), Brazil $55 \%$ and Costa Rica $49 \%$ [18, 19]. We have a higher frequency of patients with positive HR 78.7\% (55.8\% HER2+ and 22.9\% HER2-) who were often in Stage IIIB (63\% 'Luminal A', 55.5\% 'Luminal B' and $56 \%$ 'Luminal B/HER2+'). We also have a lower frequency of the 'triple negative' (12.2\%) and 'Her2-enriched' (9.1\%) subtypes.

Our overall frequency of pCR was low, that is $8.5 \%$, and is inferior to the values reported by other groups (13\%-15\%) [10, 20, 21], but their patients exhibited earlier stage disease than ours $(71 \% \mathrm{~T} 1-\mathrm{T} 2,95 \%$ N0-N1). In those patients treated with NAC, the results seem to suggest that there are differences in chemotherapy response according to intrinsic subtype. In our study, the pCR frequency was $27.5 \%$ in the 'triple-negative' group, $13.3 \%$ in 'Her2-enriched' treated with chemotherapy and trastuzumab and $13.3 \%$ in 'Luminal B/HER2+' using the same treatment. In comparison, patients with the 'Luminal A' subtype had 0 pCR, and 'Luminal B' $2.7 \%$. These differences reached a significant value compared with the Her2+ groups in which we use trastuzumab. Likewise, the triple-negative groups also showed significant differences compared with the positive hormone receptors group.

Other papers have reported improved long-term outcomes in patients with $\mathrm{pCR}$ [6, 8, 10, 20-22]. In this report, pCR was associated with a significant increase in DFS and OS rates. The German pooled analysis and CTNeoBC pooled analysis also shown these association $[10,16]$. The 'Luminal B' breast cancer has been recognised as having worst prognosis, these characteristics were similar in our cohort of patients, but superior to 'HER2- enriched' and 'basal-like tumours' [23].

The association of pCR with an improved DFS rate is observed in the literature $[10,20,21,23,25]$ and occurs in our study as well as the association with OS rate reported by Cortazar et al [21].

The immunohistochemistry-based molecular subtype distribution in our series shows important differences with the German series [10]: 'Luminal A' was $39 \%$ in theirs versus $22.3 \%$ in ours, 'Luminal B' $8.5 \%$ versus $33.5 \%$, 'Luminal B/HER2+' $17.9 \%$ versus $22.9 \%$, 'HER2-enriched' $12.8 \%$ versus $9.1 \%$, and 'triple negative' $21.7 \%$ theirs versus $12.2 \%$ ours. It is evident, therefore, that we are addressing populations whose disease possesses different characteristics and in which we can find different results. 


\section{Conclusion}

In conclusion, it is evident that for our patients, $\mathrm{pCR}$ is associated with an improved DFS and OS rate. In our cohort, achievement of pCR was more frequent in 'triple negative' and 'HER2-enriched' patients, as has been previously shown in other studies. We believe that the low pCR rate in our trial was due to the advanced cancer stages in the majority of our population ( $80.2 \%$ were Stage III). This needs to be confirmed in prospective studies. We do not have an explanation for the high frequency of HR+ tumours in our population. It could be ethnic and deserves further investigation.

\section{Conflicts of Interests}

None declared.

\section{Funding}

Instituto de Cancerología- IDC, Comprehensive Cancer Center in Colombia.

\section{Acknowledgments}

Program 'Sostenibilidad del Grupo Académico de Epidemiología Clínica 2013-2014' Sustainability Strategy. Academic Group Clinical Epidemiology.

\section{Authors' Contributions}

The concept and design of the study was contributed by Rodolfo Gómez, Carlos Andrés Ossa, Héctor García. Rodolfo Gómez, Carlos Andrés Ossa, Fernando Herazo, Carolina Echeverri, Alejo Jiménez, Jorge Madrid, Mónica Gil, Sabrina Herrera María Elvira Montoya, Gonzalo Ángel, Mauricio Borrero, Pedro Reyes, and Eduardo Gutiérrez were involved in material supply and patient referral. Data collection and processing was done by Lina Zuluaga, Johana Ascuntar. Data analysis and interpretation were performed by Rodolfo Gómez, Carlos Andrés Ossa, Héctor García. Rodolfo Gómez, Carlos Andrés Ossa, Fernando Herazo, and Héctor García were involved in the final manuscript approval.

\section{References}

1. Mauri D, Pavlidis N and loannidis JP (2005) Neoadjuvant versus adjuvant systemic treatment in breast cancer: a meta-analysis J Natl Cancer Inst 97(3) 188-194 DOI: 10.1093/jnci/dji021 PMID: 15687361

2. Robertson FM, Bondy $M$ and Yang W et al (2010) Inflammatory breast cancer: the disease, the biology, the treatment CA Cancer J Clin 60(6) 351-375 DOI: 10.3322/caac.20082 PMID: 20959401

3. Fisher B, Brown A and Mamounas E et al (1997) Effect of preoperative chemotherapy on local-regional disease in women with operable breast cancer: findings from national surgical adjuvant breast and bowel project B-18 J Clin Oncol 15(7) 2483-2493 PMID: $\underline{9215816}$ 
4. Kaufmann M, Hortobagyi GN and Goldhirsch A et al (2006) Recommendations from an international expert panel on the use of neoadjuvant (primary) systemic treatment of operable breast cancer: an update J Clin Oncol 24(12) 1940-1949 DOI: 10.1200/

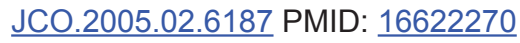

5. Goldhirsch A, Wood WC and Coates AS et al (2011) Strategies for subtypes-dealing with the diversity of breast cancer: highlights of the St. Gallen international expert consensus on the primary therapy of early breast cancer 2011 Ann Oncol 22(8) 1736-1747 DOI: $\underline{10.1093 / a n n o n c / m d r 304 ~ P M I D: ~} 21709140$ PMCID: $\underline{3144634}$

6. Rouzier R, Perou CM and Symmans WF et al (2005) Breast cancer molecular subtypes respond differently to preoperative chemotherapy Clin Cancer Res 11(16) 5678-5685 DOI: 10.1158/1078-0432.CCR-04-2421 PMID: $\underline{16115903}$

7. Loibl S, von Minckwitz G and Blohmer JU et al (2011) pCR as a surrogate in HER2-positive patients treated with trastuzumab Cancer Res 71(24 suppl) Abstract S5-S4 DOI: 10.1158/0008-5472.SABCS11-S5-4

8. Bear HD, Anderson S and Brown A et al (2003) National surgical adjuvant breast and bowel project protocol B-27 The effect on tumor response of adding sequential preoperative docetaxel to preoperative doxorubicin and cyclophosphamide: preliminary results from national surgical adjuvant breast and bo J Clin Oncol 21(22) 4165-4174 DOI: 10.1200/JC0.2003.12.005 PMID: 14559892

9. Rastogi P, Anderson SJ and Bear HD et al (2008) Preoperative chemotherapy: updates of national surgical adjuvant breast and bowel project protocols B-18 and B-27 J Clin Oncol 26(5) 778-785 DOI: 10.1200/JCO.2007.15.0235 PMID: $\underline{18258986}$

10. Von Minckwitz G, Untch M and Blohmer JU et al (2012) Definition and impact of pathologic complete response on prognosis after neoadjuvant chemotherapy in various intrinsic breast cancer subtypes J Clin Oncol 30(15) 1796-1804 DOI: 10.1200/ JCO.2011.38.8595 PMID: $\underline{22508812}$

11. Hammond MEH, Hayes DF and Dowsett M et al (2010) American society of clinical oncology/college of American pathologists guideline recommendations for immunohistochemical testing of estrogen and progesterone receptors in breast cancer Arch Pathol Lab Med 134(6) 907-922 PMID: 20524868 PMCID: 3073033

12. Wolff AC, Hammond ME and Schwartz JN et al (2007) American society of clinical oncology/college of American pathologists guideline recommendations for human epidermal growth factor receptor 2 testing in breast cancer Arch Pathol Lab Med 131 18-43 PMID: 19548375

13. Dowsett M, Nielsen TO and A'Hern R et al (2011) Assessment of Ki67 in breast cancer: recommendations from the international Ki67 in breast cancer working group J Natl Cancer Inst 103(22) 1656-1664 DOI: 10.1093/jnci/djr393 PMID: 21960707 PMCID: $\underline{3216967}$

14. Von Minckwitz G, Rezai M and Loibl S et al (2010) Capecitabine in addition to anthracycline- and taxane-based neoadjuvant treatment in patients with primary breast cancer: phase III GeparQuattro study J Clin Oncol 28(12) 2015-2023 DOI: 10.1200/ $\underline{\text { JCO.2009.23.8303 PMID: } 20308671}$

15. Ossa CA, Gomez LR and Ascuntar Tello J et al Survival of Patients with Breast Cancer Treated at the Cancer Institute of Medellin (Colombia) Between 2008 and 2012. In press

16. Von Minckwitz G, Untch $M$ and Nüesch $E$ et al (2011) Impact of treatment characteristics on response of different breast cancer phenotypes: pooled analysis of the german neo-adjuvant chemotherapy trials Breast Cancer Res Treat 125 145-156 DOI: $10.1007 / \mathrm{s} 10549-010-1228-\mathrm{x}$

17. Feldman LD, Hortobagy GN and Buzdar AU et al (1986) Pathological assessment of response to induction chemotherapy in breast cancer Cancer Res 46 2578-2581 PMID: $\underline{3697997}$ 
18. Chávrri-Guerra Y, Villarreal-Garza C and Liedke $P$ et al (2012) Breast cancer in Mexico: a growing challenge to health and the health system Lancet Oncol 13 e335-e343 DOI: 10.1016/S1470-2045(12)70246-2

19. Villareal-Garza C, Aguila C and Magallanes-Hoyos M et al (2013) Breast cancer in young women in Latin America: an unmet, growing burden Oncologist 18 1298-1306 DOI: 10.1634/theoncologist.2013-0321

20. Bonnefoi H, Litière S and Piccart M et al (2014) Pathological complete response after neoadjuvant chemotherapy is an independent predictive factor irrespective of simplified breast cancer intrinsic subtypes: a landmark and two-step approach analyses from the EORTC 10994/BIG 1-00 phase III trial Ann Oncol 25(6) 1128-1136 DOI: 10.1093/annonc/mdu118 PMID: 24618153 PMCID: $\underline{4037859}$

21. Cortazar $P$, Zhang $L$ and Untch $M$ et al (2014) Pathological complete response and long-term clinical benefit in breast cancer: the CTNeoBC pooled analysis Lancet 6736(13) 1-9

22. Jeruss J, Mittendorf EA and Tucker SL et al (2008) Combined use of clinical and pathologic staging variables to define outcomes for breast cancer patients treated with neoadjuvant therapy J Clin Oncol 26 246-252 DOI: 10.1200/JCO.2007.11.5352

23. Ades F, Zardavas D and Bozovic-Spasojevic I et al (2014) Luminal B breast cancer: Molecular characterization, clinical management and future perspectives J Clin Oncol 32 2794-2803 DOI: 10.1200/JCO.2013.54.1870 PMID: 25049332

24. Houssami N, Macaskill P and von Minckwitz G et al (2012) Meta-analysis of the association of breast cancer subtype and pathologic complete response to neoadjuvant chemotherapy Eur J Cancer 48(18) 3342-3354 DOI: 10.1016/j.ejca.2012.05.023 PMID: 22766518

25. Wolmark N, Wang J and Mamouunas E et al (2001) Preoperative chemotherapy in patients with operable breast cancer: nineyear results from a national surgical adjuvant breast and bowel project B-18 J Nat/ Cancer Inst Monogr 30 96-102 DOI: 10.1093/ oxfordjournals.jncimonographs.a003469 